\title{
Total Hip Replacement in Young Adults Less Than Fifty Year Old: Our Experience
}

\author{
Adonis Magoumou, Narcisse Dabiré, Yassir El Andaloussi, Said Abdallah, Amine Belmoubarik, \\ Rachid Ait-Mouha Karim Ahed, Nabil Omari, Ahmed Reda Haddoun, Driss Bennouna, \\ Mohamed Moujtahid, Mohamed Nechad, Mustapha Fadili
}

Department of Orthopedic Traumatology, Wing 4, Chu Ibn Rochd, Casablanca, Morocco

Email: constantcm@yahoo.fr

How to cite this paper: Magoumou, A., Dabiré, N., El Andaloussi, Y., Abdallah, S., Belmoubarik, A., Ait-Mouha K. Ahed, R., Omari, N., Haddoun, A.R., Bennouna, D., Moujtahid, M., Nechad, M. and Fadili, M. (2017) Total Hip Replacement in Young Adults Less Than Fifty Year Old: Our Experience. Open Journal of Emergency Medicine, 5, 43-74.

https://doi.org/10.4236/ojem.2017.52006

Received: November 21, 2016

Accepted: June 23, 2017

Published: June 26, 2017

Copyright ( 92017 by authors and Scientific Research Publishing Inc. This work is licensed under the Creative Commons Attribution International License (CC BY 4.0).

http://creativecommons.org/licenses/by/4.0/ (c) (i) Open Access

\begin{abstract}
Background: We report a retrospective study of 47 total prosthesis of hip put in place among the young adult of less than fifty years in the service of Traumatology and Orthopedics at the Wing IV of the CHU Ibn Rochd of Casablanca, over a period from January 2008 to March 2014, with an average rate of decline of 42 months. Results: The deliberate group of 43 patients ( 47 hips including 4 bilateral) consisted of 26 women, either $60,47 \%$ and 17 men, either 39, 53\%. The average age of our patients was 36 years. In our series, the predominant etiology has been conducted for the indication of the hip replacement was the aseptic osteonecrosis of the femoral head which has represented $31.91 \%$. With regards to the choice of implants, $85 \%$ of PTH were non-cemented, the cemented PTH has been used in $15 \%$ of cases. The Friction Torque metal/polyethylene was used in all cases. The functional outcome was appreciated by the rating of Merle of Aubigne before and after arthroplasty. The average rate of decline of 42 months, and the results were generally satisfactory. They were excellent in $27.78 \%$ of cases, very good in $19.44 \%$ of cases and good in $44.44 \%$ of cases. The results on the Pain were remarkable: the rating of the pain going 2.8 in pre-operative at 5.6 at the latest decline. The results on the walking and mobility were also good. It was noted as a complication: 4 cases of prosthetic dislocation, 1 case of aseptic descellement bipolar, 2 cases of early sepsis on hardware, 3 cases of paralysis of the sciatic external popliteal and 4 cases of periprothetiques ossification. In total, 5 total prosthesis of hip were occasions. The young age does not seem to be an obstacle to the prosthetic surgery. Conclusion: However, a major question remains concerning the distant future of these prostheses in young active subjects, because they will be submitted for many years in a job which can cause the descellement of prosthetic parts.
\end{abstract}

\section{Keywords}

Total Hip Replacement, Young Subjects, Hip Disease, Casablanca 


\section{Introduction}

The goal of total hip replacement is to replace the worn surfaces of the ball-andsocket joint. The number of total prosthesis of hip (PTH) implanted by year is in perpetual increase in the industrialized countries but also in Morocco, the quality of life is better because of the increase in the life expectancy and the availability of prostheses in the public hospitals since the introduction of the medical assistance scheme (RAMED).

The indication by excellence of the total hip remains the coxarthrose, this traditional indication limited the practice of this technique to the elderly, but the excellent results of this technique have pushed the orthopaedic surgeons to the practice in subjects of more and more young people.

However, the implantation on young patients increases the risk of iterative occasions. The pre-operative planning is therefore paramount in the choice of the surgical technique and the choice of implants.

Through this retrospective study of 43 patients ( 47 total prosthesis of hip) collected at the service of orthopaedic traumatology wing IV of the Center Hospitalier Universitaire Ibn Rochd of Casablanca, we want to relate our experience in the total hip replacement in the subject of less than 50 years, while comparing our results in the light of different data in the literature.

\section{Materials and Methods}

Our study is concerned with the reviewing of 43 patients aged less than 50 years, having benefited from 47 total prosthesis of hip between January 2008 and March 2014 in the service of orthopaedic traumatology wing IV of the University Hospital Center (CHU) Ibn Rochd of Casablanca.

The clinical information, para-clinical scalable and have been collected from the records of the sick and collected by the means of a farm, a copy of which is shown below. We have studied the data pre-therapeutic, the surgical act and suites post-operation. Our criteria of inclusions were: Patients who benefited from a total hip aged less than 50 years of age at the time of arthroplasty, autonomous patients, decline of minimum 6 months post-operative is required. Our criteria of non-inclusions were: age greater than 50 years at the time of the total hip replacement, psychomotor retardation, neuropsychiatric disorders, Comorbidities serious: dysimmunitary field, decompensated heart disease.

\section{Ethics}

Patients or their relatives gave informed consent to be part of the study.

\section{Results}

\section{Epidemiological Study}

-Age

The age of our patients was between 22 and 49 years with an average age of 36 years at the time of the intervention. 


\section{$-\operatorname{Sex}$}

In our series we note a predominance of women: 26 patients were women (either $60,47 \%) ; 17$ patients were men (either 39, 53\%). With a sex-ratio male/female of 0.65 .

\section{-Operated Side}

The right hip was operated in 24 cases, either 55, 81\% and the left hip in 15 cases, either $34,88 \%$.

Four of our patients $(9.3 \%)$ have benefited from a bilateral PTH at an average interval of 8 months.

\section{Pathological History}

-Medical History

Thirteen patients had a medical history, either $30,23 \%$, presented in the Table 1.

\section{-Medical treatment to the long course:}

Six patients $(13.9 \%)$ were treated in the long term by NSAIDS, including 1 in association with corticosteroids, 4 patients (9.3\%) were treated by a corticosteroid to the long course of which 3 in association with immunosuppressive therapy.

\section{$\checkmark$ History of the hip place:}

Ten patients of our series is $23.25 \%$ had orthopaedic history at the level of the hip place:

Osteosynthesis for fracture of the neck of the femur in 3 cases; Orthopedic treatment for fracture of the acetabulum in 1 cases; Biopsy of the hip in 2 cases; Femoral Epiphysiolyse higher in 1 cases; Bloody reduction of LCH in 2 cases including 1 associated with a pelvic osteotomy; Landfill by traction for $\mathrm{OPH}$ in 1 case.

\section{- INDICATIONS}

- The indications of total prosthesis in the hip in our series are listed in Table 2.

- Have been regarded as coxarthrose post-traumatic stress, osteoarthritis secondary to trauma of hip, former is not defined or a fracture of the acetabulum.

- Have been regarded as aseptic osteonecrosis post-traumatic, osteonecrosis secondary to a fracture of the femoral neck (failure of osteosynthesis) or to a Hip Dislocation post-traumatic stress is neglected.

Table 1. Medical history of patients.

\begin{tabular}{cc}
\hline Medical history & Number of Cases \\
\hline Diabetes (type II) & 1 \\
Genital TB & 1 \\
Obsessive-compulsive disorders & 1 \\
Asthma & 1 \\
Anxiety Disorders & 1 \\
Ankylosing spondylitis (SPA) & 5 \\
Rheumatoid Arthritis (PR) & 3 \\
\hline
\end{tabular}


Table 2. Distribution of indications of the total hip.

\begin{tabular}{|c|c|}
\hline Indication (\%) & Number of hip \\
\hline Primitive coxarthrose $(4.26 \%)$ & 2 \\
\hline \multicolumn{2}{|l|}{ Secondary coxarthrose } \\
\hline -Coxarthrose post-traumatic (14.89\%) & 7 \\
\hline -Coxarthrose on congenital dysplasia (10.64\%) & 5 \\
\hline - $\quad$ The sequelae of LCH (8.51\%) & 4 \\
\hline - $\quad$ Cotyloïdienne dysplasia $(2.13 \%)$ & 1 \\
\hline -sequelae of primitive osteochondrite of the Hip (OPH) (2.13\%) & 1 \\
\hline -sequelae of epiphysiolyse (2.13\%) & 1 \\
\hline -The sequelae of coxite tuberculous infectious $(6.38 \%)$ & 3 \\
\hline -Aseptic osteonecrosis of the femoral head (ONATF) (31.91\%) & 15 \\
\hline - $\quad$ Post-traumatic stress disorder $(12.77 \%)$ & 6 \\
\hline - $\quad$ Secondary to a corticosteroid $(2.13 \%)$ & 1 \\
\hline - $\quad$ Secondary to an ethylisme $(2.13 \%)$ & 1 \\
\hline - $\quad$ The idiopathic $(14.89 \%)$ & 7 \\
\hline -Patella tendon inflammation of the femoral neck $(2.13 \%)$ & 1 \\
\hline -Other: & 1 \\
\hline - $\quad$ Neurogenic Paraosteoarthropathie (NENA) (2.13\%) & \\
\hline -Coxites inflammatory $(23.40 \%)$ & 11 \\
\hline - $\quad$ Rheumatoid arthritis (PR) (10.64\%) & 5 \\
\hline - $\quad$ Ankylosing spondylitis (SPA) $(12.76 \%)$ & 6 \\
\hline
\end{tabular}

Among the coxarthroses secondary to a legacy of LCH (4 hips or $8.51 \%$ ), two were a LCH neglected and 2 had benefited from a surgical reduction during childhood.

The aseptic osteonecrosis of the femoral head and the inflammatory coxites accounted for more than $55 \%$.

The inflammatory coxites were constituted of the ankylosing spondylitis in $12.76 \%$ and rheumatoid arthritis in $10.64 \%$. The primitive coxarthrose was found in $4.26 \%$.

\section{Preoperatory Study}

\section{$\checkmark$ Physical activity}

The level of activity of the patients has been appreciated according to the classification in 5 grades of Devane (Table 3).

In preoperatory, $58.14 \%$ of patients were active, this is explained by the young age of the population studied.

\section{Clinical Study}

All our patients had a history made of pain and a functional discomfort to the mobility and walking. We assessed the functional outcomes of hips operated in accordance with the rating of Postel and Merle of Aubigne (LDCS). 
Table 3. Results of the patients activites in preoperatory according to the classification of Devane.

\begin{tabular}{crcc}
\hline Rank & Type of Activity & Number of Cases & Percentage \\
\hline $\mathbf{1}$ & Sedentary, depending & 0 & $0.00 \%$ \\
$\mathbf{2}$ & Semi-sedentary, domestic activities & 18 & $41.86 \%$ \\
$\mathbf{3}$ & Leisure activities, gardening, swimming & 12 & $27.91 \%$ \\
$\mathbf{4}$ & Office work, lightweight sports “social” & 8 & $18.60 \%$ \\
$\mathbf{5}$ & Physical work force, intense sport or competition & 5 & $11.63 \%$ \\
\hline
\end{tabular}

\section{-Pain}

The rating of the intensity of the pain was less than or equal to 3 points in $74.4 \%$ of cases, to 4 points in $23.4 \%$ and only a hip was rated to 5 points according to the rating of LDCS, with an average of 2.8 .

\section{-The mobility}

The rating of the mobility was less than or equal to 3 points in $68.09 \%$ and greater than or equal to 4 points in $31.91 \%$ with an average for the Mobility pre-operative of 3.

- Walking

The walk in preoperative was rated to 3 or less among $61.7 \%$ of our patients. It was rated to 4 among $31.9 \%$ of them with an average for the walk of 3.3 .

In our series, the evaluation of the preoperative LDCS had found: a preoperative LDCS was bad among 28 hips (59.57\%), poor in 15 hips (31.91\%), and finally fair among 4 hips (8.51\%).

\section{Radiological Study}

\section{-Standard Radiology}

The radiological survey was conducted on $x$-rays of the face and profile of the Hip concerned and a radiography of basin of face. It was found constantly but in a variable manner: A pinch of the line spacing; Geodes and condensation; An osteophytose capital and/or cotyloidienne.

For the ONATF, the classification of Arlet Ficat and showed 52\% of the hips in stage IV.

\section{-Computed Tomography (CT)}

Four of our patients have benefited of a CT scan of the basin.

-Magnetic Resonance Imaging (MRI)

A patient has benefited from an MRI of the basin which has shown: a bilateral osteonecrosis of the femoral head.

\section{-Study of operability}

\section{-Clinical study}

All our patients have benefited from a clinical examination of systematic and comprehensive in the search for an underlying pathology that can against-Indicate the surgical act.

The search for a home infectious (Oto-rhino-laryngologique (ENT), urinary, genital, digestive) and its treatment was systematic. 


\section{Treatment}

\section{$\checkmark$ Surgical technique}

-Preparation of the operative field

All our patients have benefited from a Preparation of the operative field on the eve of the intervention, which consisted of shaving the lower member and the pubis and a skin disinfection of the operative region by the dermal betadine before the operation.

The intervention took place in a room reserved exclusively to the aseptic surgery.

\section{-Anesthesia}

Among the $47 \mathrm{PTH}, 30$ have been put in place under general anesthesia (or 63.83\%) and 17 put in place under rachianesthesie (or $36.17 \%$ ).

-Installation of the patient

All our patients have been operated in lateral decubitus, with a sacred support pubic and to stabilize the patient during the surgical procedure.

-Tracks first:

All PTH of our series have been put in place by the track posterior external Moore.

-Additional Gestures

Of the bone gestures were required in 7 hips (14.89\%) and all bone grafts were autologous.

A ring of supports Curboul type was placed in 1 case.

\section{-Type of implanted prosthesis}

\section{According to the mode of fixation}

The PTH implanted in our patients were cemented; in 7 cases, either $14.89 \%$; not cemented in 40 cases, either $85.1 \%$ including: For 27 cases the acetabulum was screwed and for 13 cases the acetabulum was press-fit.

\section{PTH dual mobility or conventional:}

The PTH were of type "conventional" in $85 \%$ of cases and were of type double mobility in $15 \%$ of cases.

Metal/polyethylene (steel/polyethylene (PE) and cobalt-chrome/PE).

The Friction Torque steel/polyethylene represented more than $68 \%$ in our series.

\section{$\checkmark$ Different implants used}

-The sizes of implants

-Parts cotyloidiennes

The size of the COINS cotyloidiennes used is reported in the Table 4.

\section{The femoral parts}

\section{Femoral stems}

The size of the femoral stems used is reported in the Table 5.

The neck was: Short in 23 cases (48.94\%), medium in 14 cases (29.79\%), long in 9 cases (19.15\%), extra-long in 1 cases $(2.13 \%)$.

\section{Femoral heads}

Among the $47 \mathrm{PTH}$, all had a femoral head diameter of $28 \mathrm{~mm}$ except a single PTH which had a head of $22 \mathrm{~mm}$. 
Table 4. Size of parts cotyloidiennes used.

\begin{tabular}{cccccccccc}
\hline $\begin{array}{c}\text { External diameter } \\
\text { acetabulum }\end{array}$ & $\mathbf{4 4} \mathrm{mm}$ & $\mathbf{4 6} \mathbf{m m}$ & $\mathbf{4 8} \mathbf{m m}$ & $\mathbf{5 0 ~} \mathbf{m m}$ & $\mathbf{5 2} \mathbf{m m}$ & $\mathbf{5 4} \mathbf{m m}$ & $\mathbf{5 6} \mathbf{m m}$ & $\mathbf{5 8} \mathbf{m m}$ & $\mathbf{6 0} \mathbf{m m}$ \\
\hline Percentage & $2.13 \%$ & $8.51 \%$ & $29.79 \%$ & $25.53 \%$ & $10.64 \%$ & $12.77 \%$ & $6.38 \%$ & $2.13 \%$ & $2.13 \%$ \\
\hline
\end{tabular}

Table 5. Size of stemmed femoral used.

\begin{tabular}{ccccccccccccccc}
\hline Rod Size & $\mathbf{1}$ & $\mathbf{2}$ & $\mathbf{3}$ & $\mathbf{4}$ & $\mathbf{5}$ & $\mathbf{6}$ & $\mathbf{7}$ & $\mathbf{7 . 5}$ & $\mathbf{8}$ & $\mathbf{9}$ & $\mathbf{1 0}$ & $\mathbf{1 1}$ & $\mathbf{1 2}$ & $\mathbf{1 3}$ \\
\hline Percent age & $2.13 \%$ & $2.13 \%$ & $8.51 \%$ & $4.26 \%$ & $10.64 \%$ & $8.51 \%$ & $6.38 \%$ & $2.13 \%$ & $6.38 \%$ & $12.77 \%$ & $23.40 \%$ & $6.38 \%$ & $4.26 \%$ & $2.13 \%$ \\
\hline
\end{tabular}

\section{The postoperatory care:}

The thrombophylaxy was started systematically in postoperatory in all the patients on the basis of low molecular weight heparin.

\section{-Analgesics:}

The postoperatory analgesia has been ensured by administration of non-steroidal anti-inflammatory drugs (NSAIDS) and analgesics.

\section{-Rehabilitation:}

The rehabilitation has been started as soon as possible as well as the sitting position, the very day after the intervention. In the $2^{\text {nd }}$ day lifted and wandering has been accompanied using a strut. The rehabilitation was continuing in the exercises of articular mobilization and strengthening muscles by isometric contractions with an upgrade in charge protected by bequillage and under the supervision of a physiotherapist.

This rehabilitation has been to rule, among all our sick.

For patients who have had a bone graft, the charging was outlawed up to consolidation.

\section{Postoperatory Complications}

-Early complications (the first 3 months)

\section{General Complications}

No thromboembolic complications, cardiac, or early death has been noted.

\section{Local complications}

- No cases of superficial hematoma or femur fracture on prosthesis has been observed.

- We have had 1 cases $(2.13 \%)$ of Early sepsis on hardware, to J5 Post-operative. An abundant washing and curettage of the infected tissues with bacteriological sampling has been carried out. The direct examination and culture was negative. Antibiotic therapy had been established. The evolution has been good. It was a patient aged 39 years operated on the left side for coxite inflammatory. Followed for PR since the age of 10 years under prolonged corticosteroid therapy in combination with methotrexate (Observation (obs) number (no) 16).

- We have had 1 cases of paralysis of the popliteal sciatic external (EPS): (obs. $n^{\circ} 4$ ), with a good evolution. 
- In our series, 3 cases of Early dislocation of PTH have been noted, the Evolution was favorable year for all the CA:

- In 2 cases: the dislocation occurred respectively to J5 (obs. $\mathrm{n}^{\circ} 24$ ) and J17 (obs. $\left.\mathrm{n}^{\circ} 30\right)$ Post-surgery. The dislocation occurred for non-compliance of movements proscribed in the 2 cases. The reduction was made in urgency: orthopediquement in 1 case (obs. $n^{\circ} 30$ ) and in the other case, resumption of the PTH with a change in the head.

- In 1 cases: the dislocation had occurred at 1 months post-operative and was associated with a tilt of the cupule $>50^{\circ}$ (obs. $n^{\circ} 42$ ). The reduction has been made surgically after change of the head.

\section{Late complications (beyond the $3^{\text {rd }}$ month post-operative) \\ -Descellements}

We have noted 1 case of descellement bipolar aseptic occurred at 3 years post-op (obs. $\mathrm{n}^{\circ} 17$ ), having need a removal of the initial prosthesis and install a new prosthesis cemented together at the same time.

\section{-Late Dislocation}

We have listed a case of late dislocation of PTH to 7 years post-surgery, after a false movement during a bath in the Hammam (OBS. $\mathrm{N}^{\circ} 1$ ). The PTH has been resumed.

\section{-Femur fracture}

No cases of femur fracture has not been listed in our study.

\section{Results at the latest decline}

\section{Patients reviewed and average decline}

The latest decline of 32 patients (36 $\mathrm{PTH}$ ) have been reviewed and 11 patients (11 PTH) have been lost sight of. The average decline for patients reviewed was 42 months with extremes ranging from 9 to 83 months. Among the patients reviewed: 24 patients (28PTH) have been reviewed in consultation for an assessment of radio-clinic.

8 patients ( $8 \mathrm{PTH}$ ) have not been able to move for reasons not related to the PTH and have been seen at home for a clinical evaluation. The radiological analysis at the latest decline has not been able to be carried out for these patients. (Last balance sheet dating back more than 2 years and not taken into account) (Figure 1).

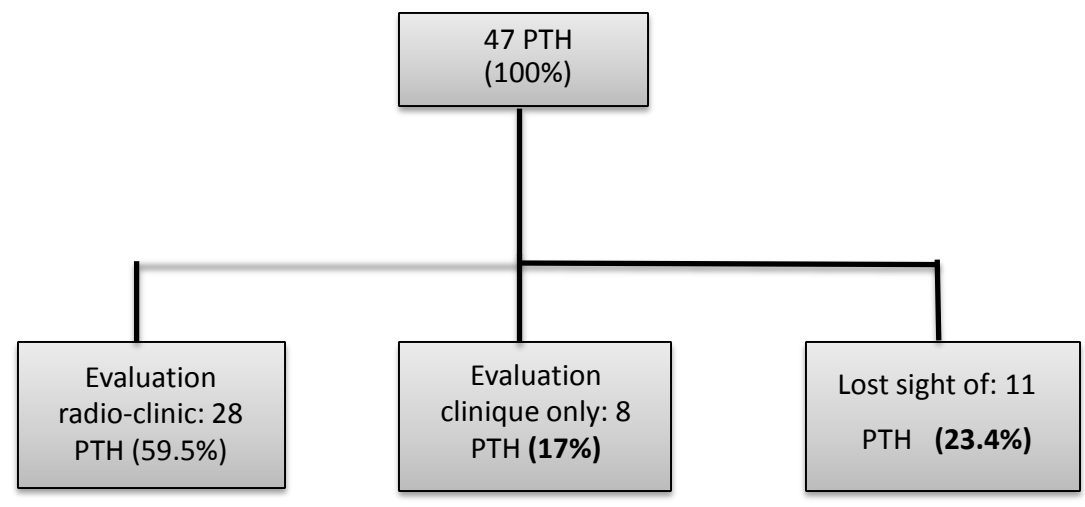

Figure 1. Distribution of patients to the latest decline. 


\section{Functional Evaluation}

For patients reviewed, we resumed the criteria of Postel and Merle of Aubigne (LDCS), in order to assess the clinical condition of the patient and the function of their hip after decline.

\section{Results on the Pain}

The average rating of the pain to the last decline was 5.63. The latest decline $69.44 \%$ of hips were painless.

\section{Results on the mobility}

The average rating of the mobility in the last decline was of 5.08.

\section{Results on the walk}

The rating of the walk to the latest decline was 5.4 on average.

\section{Score overall LDCS and appreciation to the latest decline}

The score LDCS average overall to the decline was 16.1.

The functional outcome global according to the scoring LDCS, at the average rate of decline of 42 months, was excellent in $27.78 \%$ of cases, very good in $19.44 \%$ of cases and good in $44.44 \%$ of cases, fair in $2.78 \%$ of cases, poor in $2.78 \%$ of cases, wrong in $2.78 \%$ of cases (Figure 2 ).

We have grouped the functional results assessed according to the criteria of Postel-Merle of Aubigne (LDCS) by: Satisfactory for the excellent results, very good and good; Unsatisfactory for the results passable, poor and ill. The results were generally satisfactory (91\%) to the average rate of decline of 42 months.

\section{Comparison of preoperative LDCS and the latest decline}

The average gain of the LDCS global at the latest decline was 7 points compared to the preoperative state. Among the items the score of the LDCS the gain the higher was the item "pain", it went from 2.8 to 5.6.

\section{* Radiological Evaluation}

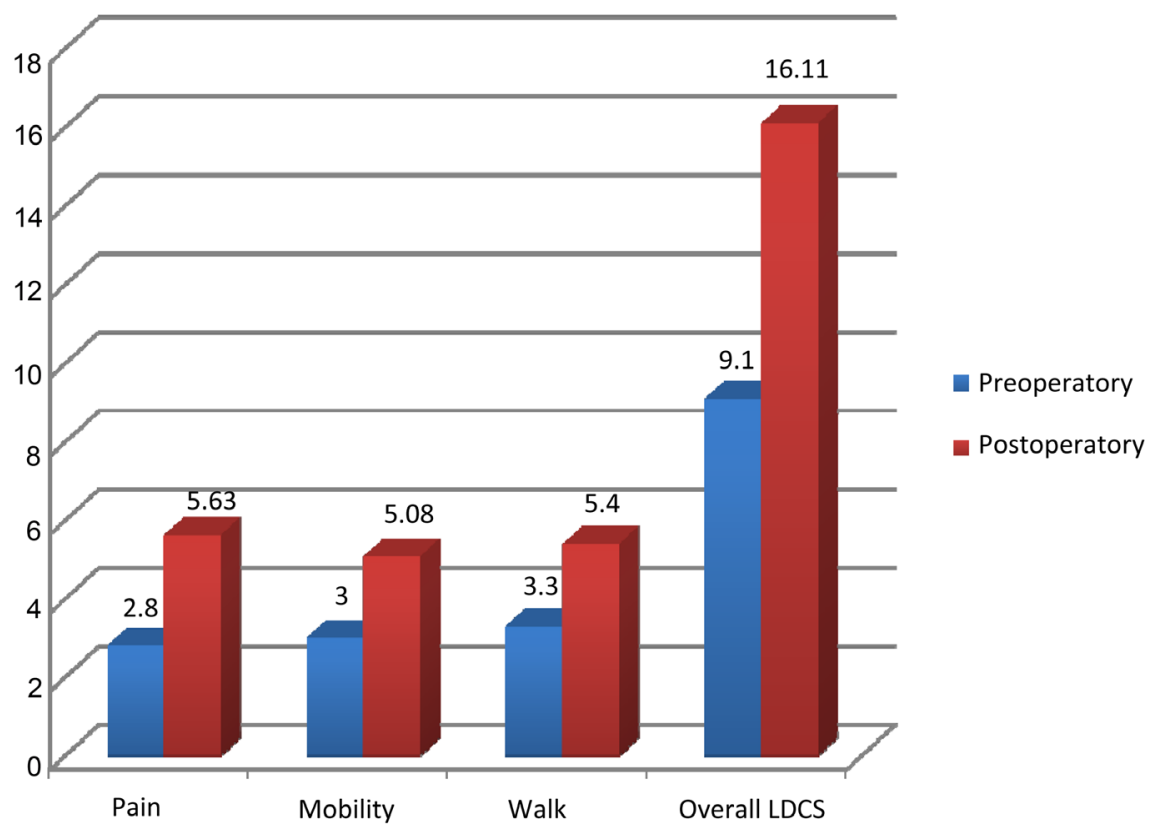

Figure 2. Comparisons of the score LDCS means before and after total hip replacement. 
The radiological assessment has been based on x-ray images of the basin of strict face as well as radiographs of the hip surgery of the face and profile taking the totality of the prosthesis.

A careful study of the successive radiographs and their confrontation with the cliches post-operative, earlier had for the purpose of the search for signs of complications.

The radiological shots have been analyzed according to the following criteria: at the level of the workpiece cotyloidienne, we checked:

- The angle of tilt of the Cup by report to the BI Line ischiatic. It is normally of $45^{\circ}$.

- The position of the acetabulum by report to the line innominee (Protrusion) and the upper part of the valve stem hole. It is normally $<2 \mathrm{~mm}$.

The liseres were analyzed in the 3 areas of Lee and Charnley. At the level of the femoral exhibit, we checked:

- The position of the workpiece by femoral report to the axis of the femur: varus valgus, or normo-focused.

- Tail of the cement.

The femoral liseres were analyzed in the 14 zones of Gruen.

For the PERI ossification prosthetic-it has used the classification of Brooker.

\section{In post-procedure}

We have studied the radiographs of control of the post-operative of all patients (47 PTH).

$\checkmark$ At the level of the Prosthetic acetabular

- 30 cases had a slope between $42^{\circ}-45^{\circ}$.

- 16 cases had a slope between $46^{\circ}-50^{\circ}$.

- A case of vertical cup with an angle $>50^{\circ}$ has been noted.

$\checkmark$ At the level of the femoral exhibit

- Three PTH had a rod in a varus.

- Two PTH had a rod in valgus.

- The STEM was normo-focused in $42 \mathrm{PTH}$.

No border line has been found in post-operative immediate.

\section{The last decline:}

It is recalled that the $\mathrm{x}$-ray analysis focuses on $28 \mathrm{PTH}$, the results are the following:

\section{$\checkmark$ At the level of the Prosthetic acetabular:}

No cases of verticalisation of the Cup was noted. All the wells had a good positioning.

No wear has been observed at the level of the acetabulum to the last decline.

$\checkmark$ At the level of the femoral part:

- 1 case of varisation of the femoral stem.

It was found 2 case of ossification peri-prosthetic appliances not having need for surgical recovery, according to the classification of Brooker:

- 1 case was of grade II: patient operated for neurogenic paraosteoarthropathie (obs. $n^{\circ} 32$ ) associated with a score of LDCS to 11 ; 
- 1 case was in Grade I: patient operated for coxarthrose post-traumatic (obs. $\left.\mathrm{n}^{\circ} 41\right)$.

In addition no sign pointing toward a descellement has been noted.

At total after an average rate of decline of 42 months:

Five PTH on the 47 implanted (10.6\%), have undergone a surgical recovery:

4 times with a change of the implant and a resumption without change of implant.

Late complications (beyond the $3^{\text {rd }}$ month post-operative)

-Descellements

We have noted 1 case of descellement bipolar aseptic occurred at 3 years post-op (obs. $\mathrm{n}^{\circ} 17$ ), having need a removal of the initial prosthesis and install a new prosthesis cemented together at the same time.

\section{-Late dislocation}

We have listed a case of late dislocation of PTH to 7 years post-surgery, after a false movement during a bath in the Hammam (obs. $n^{\circ} 1$ ). The PTH has been resumed.

-Femur fracture the post-operative

No cases of femur fracture has not been listed in our study.

Results at the latest decline

-Patients reviewed and average decline

The latest decline 32 patients (36 PTH) have been reviewed and 11 patients (11 PTH) have been lost sight of. The average decline for patients reviewed was 42 months with extremes ranging from 9 to 83 months.

\section{Functional evaluation:}

For patients reviewed, we resumed the criteria of Postel and Merle of Aubigne (LDCS), in order to assess the clinical condition of the patient and the function of his hip after decline.

\section{-Results on the pain:}

The average rating of the pain to the last decline was 5.63. The latest decline $69,44 \%$ of hips were painless.

\section{Results on the mobility:}

The average rating of the mobility in the last decline was of 5.08.

\section{Results on the walk:}

The rating of the walk to the latest decline was 5.4 on average.

\section{-Score overall LDCS and appreciation to the latest decline:}

The score LDCS average overall to the decline was 16.1 .

The global functional outcome according to the scoring LDCS, at the average rate of decline of 42 months, was excellent in $27.78 \%$ of cases, very good in $19.44 \%$ of cases and good in $44.44 \%$ of cases, fair in $2.78 \%$ of cases, poor in $2.78 \%$ of cases, wrong in $2.78 \%$ of cases (Figure 2 ).

We have grouped the functional results assessed according to the criteria of Postel-Merle of Aubigne (LDCS) by:

Satisfactory for the excellent results, very good and good;

Unsatisfactory for the results passable, poor and ill. 
The results were generally satisfactory $(91 \%)$ to the average rate of decline of 42 months.

\section{Comparison of preoperative LDCS and the latest decline}

The average gain of the LDCS global at the latest decline was 7 points compared to the preoperative state. Among the items the score of the LDCS the gain the higher was the item "pain", it went from 2.8 to 5.6.

\section{Radiological evaluation}

The radiological assessment has been based on x-ray images of the basin of strict face as well as radiographs of the hip surgery of the face and profile taking the totality of the prosthesis.

A careful study of the successive radiographs and their confrontation with the cliches post-operative, previous had for the purpose of the search for signs of complications.

The radiological shots have been analyzed according to the following criteria: at the level of the workpiece cotyloidienne, we checked:

- The angle of tilt of the Cup by report to the BI Line ischiatic. It is normally of $45^{\circ}$.

- The position of the acetabulum by report to the line innominee (Protrusion) and the upper part of the valve stem hole. It is normally $<2 \mathrm{~mm}$.

The liseres were analyzed in the 3 areas of Lee and Charnley. At the level of the femoral exhibit, we checked:

- The position of the workpiece by femoral report to the axis of the femur: varus valgus, or normo-focused.

- Tail of the cement.

The femoral liseres were analyzed in the 14 zones of Gruen.

For the PERI ossification prosthetic-it has used the classification of Brooker.

\section{-In post-procedure}

We have studied the radiographs of control the post-operative of all patients (47 PTH).

$\checkmark$ At the level of the prosthetic acetabular

- 30 cases had a slope between $42^{\circ}-45^{\circ}$.

- 16 cases had a slope between $46^{\circ}-50^{\circ}$.

- A case of vertical cup with an angle $>50^{\circ}$ has been noted.

$\checkmark$ At the level of the femoral exhibit

- Three PTH had a rod in a varus.

- Two PTH had a rod in valgus.

- The STEM was normo-focused in $42 \mathrm{PTH}$.

No border line has been found in post-operative immediate.

\section{-The last decline:}

It is recalled that the $\mathrm{x}$-ray analysis focuses on $28 \mathrm{PTH}$, the results are the following:

\section{$\checkmark$ At the level of the prosthetic acetabular:}

No cases of verticalisation of the Cup was noted. All the wells had a good positioning. 
No wear has been observed at the level of the acetabulum to the last decline.

$\checkmark$ At the level of the femoral part:

- 1 case of varisation of the femoral stem.

It was found that 2 case of ossification peri-prosthetic appliances not having need for surgical recovery, according to the classification of Brooker:

- 1 case was of grade II: patient operated for neurogenic paraosteoarthropathie (obs. $\mathrm{n}^{\circ} 32$ ) associated with a score of LDCS to 11 ;

- 1 case was in Grade I: patient operated for coxarthrose post-traumatic (obs. $\left.\mathrm{n}^{\circ} 41\right)$.

In addition no sign pointing toward a descellement has been noted.

At total after an average rate of decline of 42 months.

Five PTH on the 47 implanted (10.6\%), have undergone a surgical recovery. 4 times with a change of the implant and a resumption without change of implant.

\section{Discussion}

\section{Indications of the PTH}

\section{-General information on indications}

The indications of the PTH remain dominated by the coxarthrose [1]-[6], but the main objective of the PTH is to combat the pain and to improve the function of the hip, thereby it finds its place in a lot of other traumatic pathology and degenerative diseases of the hip.

In France, the National Agency for the development of the Medical Assessment (ANDEM) [6] has made the following recommendations on the indications of the PTH:

$\checkmark$ For the coxarthrose:

The PTH is indicated in the functionally coxarthroses causing a severe disability insufficiently daily improved by a medical treatment well led, after an observation period of a few weeks to a few months.

$\checkmark$ For fractures of the neck of the femur:

No indication of the PTH in the fractures non-displaced from the neck of the femur.

In the cases of fractures in coxa Vara, beyond 70 years, a PTH can be used. However, before 50 years, the surgical treatment must give preference to the osteosynthesis.

In the United States, NIH (National Institutes of Health) has recommended the installation of arthroplasties total hip (ATH) for patients with chronic pain of the hip with alteration of the Quality of Life. The Glory (Global Orthopaedic Registry), an international registry of patients who received an ATH in first intention, had found that the selection criteria for an ATH varied in functions of countries of patients and surgeons. However, there is no international consensus for the indications of the PTH [7].

The total hip replacement is generally indicated in the symptomatic coxarthroses resistant to conservative treatment [4]. 


\section{Epidemiological data}

More than 1 million of total hip replacement are performed each year in the world, and this figure is expected to double in the next two decades. The rate of ATH of first intention has increased by 50 per cent in the United States between 1990 and 2002. In the UK between 2005 and 2010, this rate has experienced an increase of $16 \%$ and similar increases have been noted in Finland and Norway [7].

Kurtz, et al., have made a projection on the period from 2005 to 2030 in the United States. They have used the data from the Nationwide Inpatient Sample (NIS) to formulate a model allowing for a projection of the number of cases per year and predict an increase in the number of ATH of first intention to $174 \%$ [8]. Kurtz, et al., in another study, using the same method, on the period 2010 to 2030 , predict a $50 \%$ increase in the number of ATH in younger patients [29].

In Morocco, an increase in acts of total hip replacement was also observed, especially since the introduction of the system of medical assistance (RAMED) ensuring an availability of the implants in the public hospitals.

The prosthetic surgery Hip in constant increase, also concerns the subjects of more and more young and active [7] [9] [10].

The current control of operational techniques, the improvement of drawings and quality of materials of prostheses have largely contributed to these increases of settlements [11].

\section{-Age}

The age as epidemiological element is important to take into consideration in the installation of a PTH. It is an important factor determining the functional outcome and the longevity of the prosthesis [32]. The results of the PTH before 50 years of age are variously assessed in the literature. It is traditional to say that they are overall less better on the long term than those of an older population [12]-[22].

In fact, youth patients seek mechanically their prosthetic way more important. Thus, for Johnsson, each decade of less during the intervention increases the relative risk of descellement of 1.8 [23] (Table 6).

The average age in our series is 36 years, she joined the Series P 32 of the CHU Ibn Rochd [44] and is lower than those of the other series [32]-[42]. This lesser average age could be explained by the young age of the Moroccan population compared to the western population and by the frequency of pathologies affecting the young subject in our context: coxites inflammatory, coxarthrose posttraumatic.

\section{-Sex}

Classically, there is a predominance of women among patient candidates in a PTH [1] [7]. The female sex was predominant in our series, this joined the series of Aldinger [13], Chana [19] and Schmitz [20], Nich [25] and Archibeck [26] (Table 7).

To Woo and Morrey [27], the rate of dislocation is significantly higher 
Table 6. Comparison of the average age with the series of less than 50 years.

\begin{tabular}{cccc}
\hline & Year & Numbers of cases & Average Age (years) \\
\hline $\begin{array}{c}\text { Delaunay } \text { et al. [32] } \\
\text { Roof series 32 of the CHU }\end{array}$ & 2008 & 73 & 40.7 \\
Ibn Rochd (P32 CHUIR) [44] & 2009 & 31 & 36 \\
Aldinger et al. [33] & 2009 & 141 & 47 \\
Migaud et al. [34] & 2011 & 30 & 39.8 \\
Hwang et al. [35] & 2011 & 70 & 39.8 \\
Teusink et al. [36] & 2012 & 118 & 40.5 \\
Takenaga et al. [37] & 2012 & 100 & 40.1 \\
Innmann et al. [38] & 2013 & 91 & 42 \\
Chana et al. [39] & 2013 & 110 & 45 \\
Schmitz et al. [40] & 2013 & 126 & 37.6 \\
Channel Babovic et al. [41] & 2013 & 50 & 38.9 \\
Ryan et al. [42] & 2014 & 72 & 43.1 \\
Our series & 2015 & 43 & 36 \\
\hline
\end{tabular}

Table 7. Distribution of PTH in young subjects on the basis of sex among various authors.

\begin{tabular}{ccccc}
\hline Authors & Year & $\begin{array}{c}\text { Numbers } \\
\text { of cases }\end{array}$ & $\begin{array}{c}\text { Percentage } \\
\text { of men (H) (\%) }\end{array}$ & $\begin{array}{c}\text { Percentage of } \\
\text { women (F) (\%) }\end{array}$ \\
\hline Nich et al. [15] & 2006 & 23 & 43.4 & 56.6 \\
Archibeck et al. [16] & 2006 & 91 & 49 & 51 \\
Delaunay et al. [12] & 2008 & 73 & 79.4 & 20.6 \\
Series P32 CHUIR [14] & 2009 & 31 & 51,61 & 48,38 \\
Aldinger et al. [13] & 2009 & 141 & 48.9 & 51.1 \\
Migaud et al. [14] & 2011 & 30 & 83.3 & 16.7 \\
Hwang et al. [15] & 2011 & 70 & 81.4 & 18.6 \\
Teusink et al. [16] & 2012 & 118 & 51.7 & 48.3 \\
Takenaga et al. [17] & 2012 & 100 & 63 & 37 \\
Innmann et al. [18] & 2013 & 91 & 67 & 33 \\
Chana et al. [19] & 2013 & 110 & 47.3 & 52.7 \\
Schmitz et al. [20] & 2013 & 126 & 48.4 & 51.6 \\
Ryan et al. [12] & 2014 & 88 & 51.4 & 48.6 \\
$\quad$ Our series & 2015 & 43 & 39.5 & 60.47 \\
\hline
\end{tabular}

among women $(3.8 \% \mathrm{~F}$ against $2.5 \% \mathrm{H})$, same as for Turner $(5.5 \% \mathrm{~F}$ against $2.8 \% \mathrm{H}$ ) [28]. This difference can be attributed to a greater muscle weakness [27]. The predominance of women is even more clear in the late Luxations [29].

The male sex as to him, would be associated with a rate of aseptic descellement to be higher. The fact that the men are on an average are heavier and prac- 
tice of physical activities are more important than women of the same age, would entail a solicitation that are more important of the implant leading to terms to the descellement [30] [31].

\section{C-indications:}

When a HIP is reached by a pathological process (coxarthrose primitive or secondary, osteonecrosis of femoral head, coxites ... etc.) the clinical expression is generally summarized to 3 functional signs associated with various degrees: pain, loss of mobility and lameness. These signs are reflected by a disability in the life of the sick. The indication of arthroplasties, is essentially based on the functional discomfort of patients [32].

The pathologies leading to the establishment of a total hip are multiple and well known. In young patients, the pathologies responsible of disability are specific. The legacies of diseases of the childhood are: primitive osteochondritis of the Hip (OPH), congenital dislocation of hip ( $\mathrm{LCH})$, Aseptic osteonecrosis of the femoral head in transplant recipients of marrow, sickle cell anemia, corticosteroids for various ailments, severe asthma or other. These are also of rheumatic diseases (juvenile idiopathic arthritis (JIA), ankylosing spondylitis (SPA), rheumatoid arthritis (PR)), the villo synovitis-nodular and quickly coxarthroses scalable. The sequelae of trauma also represent an important part: fractures of the acetabulum and the neck of the femur. The sequelae of pathologies of the children constitute a population where the morphological alterations are frequent and may complicate the surgical management [11].

In our series The ONATF was predominant which combined the results of Delaunay [12], Migaud [14], Hwang [15], Schmitz [16], Ryan [22] and Kim [33] (Table 8).

Table 8. Comparison of etiologies having conducted to the indication of PTH.

\begin{tabular}{|c|c|c|c|c|c|c|c|c|c|c|}
\hline Series & $\begin{array}{c}\text { Year of } \\
\text { Publication }\end{array}$ & $\begin{array}{l}\text { \# of } \\
\text { hips }\end{array}$ & $\begin{array}{c}\text { Primitive } \\
\text { Coxarthrose } \\
(\%)\end{array}$ & $\begin{array}{l}\text { Coxarthrose } \\
\text { post-traumatic } \\
\text { stress (\%) }\end{array}$ & $\begin{array}{c}\text { Coxite } \\
\text { inflammatoire } \\
(\%)\end{array}$ & $\begin{array}{c}\text { Congenital } \\
\text { Dysplasia } \\
(\%)\end{array}$ & $\begin{array}{l}\text { ONATF } \\
(\%)\end{array}$ & $\begin{array}{c}\text { Epiphysiolyse } \\
\text { (\%) }\end{array}$ & $\begin{array}{c}\text { OPH } \\
(\%)\end{array}$ & $\begin{array}{l}\text { Septic } \\
\text { arthritis } \\
\text { of the } \\
\text { hip (\%) }\end{array}$ \\
\hline Delaunay et al. [12] & 2008 & 83 & 23 & 4.8 & - & 27.7 & 42 & - & 2.4 & - \\
\hline Series P32CHUIR [24] & 2009 & 35 & 11.42 & 22.85 & 34.27 & - & 25.7 & - & - & 5.70 \\
\hline Aldinger et al. [23] & 2009 & 154 & 31 & 5 & 1 & 33 & 19 & - & - & - \\
\hline Migaud et al. [24] & 2011 & 39 & 2.56 & 2.56 & - & 38.4 & 51.3 & - & 5.1 & - \\
\hline Hwang et al. [25] & 2011 & 78 & 7.7 & - & 7.7 & 7.7 & 72 & - & - & 2.5 \\
\hline Kim et al. [33] & 2011 & 228 & 14 & - & 4.5 & 1.95 & 66 & - & - & 11 \\
\hline Teusink et al. [16] & 2012 & 144 & 20.83 & 4.86 & 8,97 & 12.5 & 26.4 & 6.25 & 4.86 & 0.7 \\
\hline Takenaga et al. [17] & 2012 & 115 & 34 & 7.8 & 2.61 & 12.2 & 30.5 & 1.73 & 7 & 0.87 \\
\hline Innmann et al. [18] & 2013 & 100 & 38 & 6 & 4 & 27 & 18 & - & - & - \\
\hline Chana et al. [19] & 2013 & 120 & 63.3 & - & 3.3 & 25 & 4.2 & 4.2 & - & - \\
\hline Schmitz et al. [20] & 2013 & 152 & 9.9 & 5.3 & 10.5 & 21.7 & 26.3 & 3.3 & 7.2 & 3.3 \\
\hline Ryan et al. [22] & 2014 & 88 & 5.7 & 5.7 & 9.2 & 4.5 & 67 & 3.4 & 1.1 & 3.4 \\
\hline Our series & 2015 & 47 & 4.26 & 14.89 & 23.40 & 10.64 & 31.9 & 2.13 & 2.13 & 6.38 \\
\hline
\end{tabular}


The impact of the different aetiologies in the chance of the PTH and how they may influence the results of surgical, however remains unclear in the literature [22].

During the ONATF, the overall results of the PTH are classically less better in particular subjects under 50 years of age. In these young people patients with osteonecrosis aseptic, of anatomical differences compared to the primitive coxarthrose have been observed, leading some surgeons to propose shoots on measurement in order to adapt the implant to the patient in the hope of a better long-term Outcome [34] [35].

Radl et al. [36], in a retrospective study, have assessed the results of a femoral stem which is not cemented in young patients, made for coxarthrose (49 patients) and other for aseptic osteonecrosis (31) patients with Ficat stage III and IV), the average decline was 6 years. Using the technique EBRA (Einzel-Bild roentgen-analysis), a method of analysis assisted by computer to measure the displacement of implants, they noted a migration of the rod of $1.5 \mathrm{~mm}$ among operated for osteonecrosis versus $0.6 \mathrm{~mm}$ among those operated coxarthrose ( $p$ $<0.001)$. The analysis of the survival of the stem at the latest decline, with as event revision of the rod, was $74 \%$ among the group osteonecrosis versus $98 \%$ among the group coxarthrose. They have suggested that this difference could be attributed to a decrease in the stock of bone peri-prosthetics occurred during the osteonecrosis.

However, Ince et al. [37], in a retrospective study using the same method of analysis of implants (EBRA), have evaluated the results of the 41 young patients who had a non-PTH cemented (porous coating), all made for osteonecrosis advanced and they have found no revision of the rod or descellement (average rate of decline of 7 years). Similar results have been found by Min et al. [38], among young people under the age of 55 years with osteonecrosis of the femoral head, the rate of survival of the femoral stem was $95 \%$ to 10 years. However, the authors recommend a radiological monitoring particularly attentive in these patients treated for osteonecrosis aseptic.

In the case of osteonecrosis secondary to a corticosteroid treated by a PTH which is not cemented, biological anchoring is reduced because the corticosteroids directly inhibit osteoblasts and stimulate bone resorption. It has been shown that the results of the PTH for idiopathic ONA or post-traumatic stress are better than in the case of prolonged corticosteroid. It is therefore important to know the origin of the osteonecrosis to estimate the survival of the implant [35].

In our sample, the inflammatory coxite was the $2^{\text {nd }}$ etiology in terms of frequency $(23.40 \%)$ leading to the installation of hip replacement and was represented by the SPA $(12.76 \%)$ and the PR (10.64\%). The use of the PTH in the inflammatory coxites in our series and that of p32 (34.27\%) [24] was more frequent in relation to other western series [33] [36] [37] [38] [39] [40] [42] and to the two Korean series [15] [33]. An early care and adequate inflammatory pathologies in our context by the biotherapies (anti-TNF) would delay the disabil- 
ity and the surgery Prosthetics. These therapies are costly and are unfortunately not in the scope of more of the majority of our patients. The popularization of the joint arthroplasty surgery remains the last way to improve the prognosis of functioning and quality of life of these patients.

The inflammatory coxites during the ankylosing spondylitis and rheumatoid arthritis, occur in patients at a very young age and are most often bilateral. The surgery must be fairly early, before that the deletions joints are major (ankylosis, acetabular protrusion) and are not accompanied of surgical difficulties [29].

In the course of the PR, it has been reported that results in the long-term of the PTH cemented showed a high rate of sepsis and revision for descellement [29]. Eskelinen et al., in their series based on the Finnish register, have studied 2557 PTH carried out in the framework of a PR, patients were all under the age of 55years. They noted that the risk of revision was more important for the femoral stems cemented that for those posed without cement [40]. The Hip arthritis is characterized by the frequency and timeliness of loss of bone substance on the two slopes of the articulation, this bone loss would be partly responsible for the aseptic descellements [41]. In addition, the PR is known as aggravating factor of infectious risks, through the auto character-IMMUN pathology and of therapeutic used in this context. Nevertheless, it is recommended to stop or NSAIDS, neither the corticosteroids, nor the disease modifying antirheumatic drugs (DMARDS) including methotrexate, before surgery [41].

The SPA is willingly responsible for an enraidissement, or even of a true ankylosis in a quarter of cases. The patients are usually operated young, between 35 and 40 years. Installing a PTH may require additional gestures: tenotomie adductor, correction of a contracture of the Knee... etc. The suites can be complicated by the appearance ossifications periprothetiques which limit the mobility in $12 \%$ to $45 \%$ of cases in the literature; they are rarely voluminous (8 to 23 per cent of classes III and IV of Brooker) and lead exceptionally at the reankylose [41].

In the course of arthroplasties total hip on coxarthrose post-dysplastic, the major problem encountered is the reconstruction of the acétabulum [42]. In effect, the congenital dysplasia of the Hip can lead to severe anatomical modifications of the articulation of the hip. These changes increase the surgical difficulties and can also threaten the long-term survival of the implant prosthetics [43]. Pidhorz Sedel et al., have analyzed 1347 PTH with an average rate of decline of 6.7 years. The coxarthrose post-dysplastic represented $27 \%$ of the indications of arthroplasties of this series. The PTH on cervical dysplasia posed problems of surgical technique which interfered more on the result that the quality of the materials and of the friction torque: $35 \%$ of dysplasias had need a transplant acetabular [44].

In our series, the coxarthrose post-dysplastic represented 10.64\% (5 hips) Indications. Among the 5 hips dysplastic, both hips (4.2\%) had needed an acetabular reconstruction by transplantation Autologous bone.

The PTH on congenital dysplasia of the Hip would be associated with a higher 
risk of dislocation that the PTH on primitive coxarthrose, probably due to the relative lack of abducteurs muscles but also due to the diameter of the acetabulum often imposing cupules of small size and therefore of prosthetic heads of small diameter [45]. Thillemann et al., in their series of 56087 PTH, based on the Danish Registry of arthroplasties have compared the results of the PTH carried out for coxarthroses primitives (96\%) to those of the aftermath of the pathologies of the children (cotyloidienne dysplasia (1.6\%), LCH (1.0\%), epiphysiolyse $(0.5 \%)$, OPH (0.7\%)). Patients with cotyloidienne dysplasia had a higher risk of recovery for a dislocated prosthesis during the 6 months post-operative compared to patients operated for coxarthrose primitive (relative risk $=2.8$ ). In the Group of LCH this risk was not high in relation to the group primitive coxarthrose [46]. By contrast, Furnes et al., have reported in their study a higher risk recovery for dislocation in this group (LCH) [47].

In our series of a hip dysplastic (2.13\%), was resumed for a dislocated early prosthetic. The dislocation occurred in a context of non-compliance of luxant movements.

PTH on cervical dysplasia remains a challenge for the surgeon. A pre-adequate planning and an appropriate surgical technique, are essential to ensure a better outcome in the long terms in these patients [42] [43] [45].

In our series among the coxarthroses on congenital dysplasia (5 hips), 4 were sequellaires, a LCH of childhood.

The screening of the LCH at birth, although compulsory, is often neglected. In addition, it remains very little known or poorly practiced by physicians and the auxiliary health. This complicates the supported and the prognosis. The progress to be made in our context also concern well the time diagnosis that the time taken to load.

In our study, a patient (2.13\%) had benefited from a PTH for para-neurogenic osteoarthropathie (NENA).

The NENA was following in our patient to a head trauma, it has been seen at the stage of ankylosis. The para-neurogenic osteoarthropathie or neurogenic osteomes of hip are ossifications periarticulaires heterotypic intracapsulaires secondary to a nerve lesion central or peripheral. It is a complication often asymptomatic incidentally discovery during a radiological examination. In our context, our patients are often supported at a late stage [68]. They have a functional impact important due to the limitation which articular can evolve up to the Ankylosis [48] [49] [50]. Several surgical techniques are used to operate the NENA, the most used is the arthrolyse with excision. More rarely can realize a prosthetic replacement in the event of destruction articular. The choice of the time of the surgery is important. It should wait for the maturation of the ostéome according to some authors, whereas other advocates a surgery early more [48] [49].

\section{Preoperatory Data}

-Comparison of the average score LDCS with the literature

In our study, the functional assessment pre and post-operative was conducted by the LDCS (Table 9). 
Table 9. Comparison of the average score of the Scoring LDCS in preoperative and the latest decline

\begin{tabular}{ccc}
\hline Series & Average score preoperative & Average score at the latest decline \\
\hline Nich et al. [25] & 11.7 & 16.2 \\
Delaunay et al. [12] & 11.1 & 17.4 \\
Series P32 [24] & 9.65 & 13.9 \\
Courpied et al. [51] & 10.1 & 17.1 \\
Vidalain et al. [52] & 10.9 & 17.4 \\
Our series & 9.1 & 16.1 \\
\hline
\end{tabular}

The average gain in the last decline was 7 points compared to the preoperative state. The average gain of our series was higher than that of the series P32, and was comparable to the other series of the literature. The average gain of the pain was remarkable, from 2.8 in pre-operative at 5.6 at the average rate of decline of 42 months, thus improving the quality of life of these young patients. The mobility and the walking were also improved in our patients.

\section{Radiological study}

The imaging plays a major role in the preoperative planning of prostheses, in their monitoring and in the search for possible complications at a distance.

\section{Preoperative evaluation}

The radiological cliches of the Hip provide essential information on the pathology and the model and the size of the prosthesis the more appropriate as well as the technical gestures such as the depth of the acetabular trimming, the level of resection of the femoral neck, positioning and orientation of the acetabulaires components and femoral [6] [53].

The preoperative planning, to determine the positioning of the cup and determine the femoral pivot adapted, requires a radiological balance sheet (Radiography: Pool facing, pathological hip face and profile) which the scale must be known in order to be able to use the layers of same magnification. The possible complementary Bone gestures are also studied through the Radiography: resection of osteophytes, osteotomy of the greater trochanter, bone grafting and acetabular strengthening. The preoperative radiography also allows account to be taken of any anomaly that may be a fear of a bad mounting and orientation [53].

The quality is also an important parameter in the choice of the prosthesis. It is the X-ray, which crudely reflects the state of bone as well as its architecture [6].

The telemetry can be performed to search for the reasons of the unequal length between the two States. Following the habits of surgeons, this examination may be carried out in a systematic manner or occasional. An MRI is performed in cases of osteonecrosis to ensure the diagnosis, assess the extent of necrosis and check the status of the opposite hip. The scanner is used when the geometry of the acetabulum and/or of the femur presents an Anatomic variation, particularly in young subjects [6]. 


\section{Postoperative control}

The radiological assessment is an essential complement of clinical follow-up of a hip replacement. It allows us to trace the main complications including the wear and the descellement which are inevitable, particularly in young subjects who have a higher life expectancy [41] [42].

In our series it was noted in the latest decline, a case of varisation of the stem but without sign of associated descellement.

\section{Search for complications}

The standard radiographic balance sheet also made the diagnosis of possible complications: descellement, osteolysis periprothetique, wear, instability, heterotypic ossification, and in a context that is often more acute periprothetique fracture or rupture of the implant.

\section{Treatment}

\section{Anesthesia}

The prosthetic surgery is a heavy surgery and hemorrhagic, may commit the vital prognosis. This surgery has largely benefited from recent progress of Anesthesia and resuscitation in particular in the field of transfusion economy (autologous transfusion programd (TAP), preoperative prescription of erythropoietin (EPO), devices for intraoperative recovery (RPO) [54] [55].

The two modalities of anesthesia used in the hip prosthetic surgery are: the general anesthesia (AG) and regional anesthesia (ALR) (rachianesthesie, epidural anesthesia).

The rachianesthesie is the technique of ALR most used for the installation of PTH. The choice between the different modalities anesthetic is still widely debated [55].

The meta-analysis of Rodgers et al., appealed for a reduction of thromboembolic risk, respiratory infections, transfusion needs in case ALR by report to the AG [56]. The meta-analysis of Mauermann et al., on the anesthesia during the total hip replacement, confirmed most of these results [57].

Other studies have shown that regional anesthesia is associated with analgesia the post-operative higher compared to the AG. In addition, the ALR shows a low incidence of nausea and vomiting [58] [59] [60]. In the Dutch Recommendations of 2011 for the total hip replacement, the ALR was advocated as a technique of Anesthesia [61].

However, the ALR often cause a urinary retention and a hypoblood pressure [59] [60].

For the acts of long duration and complexes such as times of total hip prostheses, general anesthesia is preferred [54] [55].

Outside of customary field problems in anesthesia (diabetes, heart disease, etc.), specific pathologies such as rheumatoid arthritis and ankylosing spondylitis can inquire a few problems: difficulty of intubation, poor tolerance to the Pain, risks associated with therapeutic with long course in these patients [55].

In our series, the general anesthesia was the most used with a rate of $63.83 \%$. The rachianesthesie has been used in $36.17 \%$ of cases. 


\section{Antibioprophylaxis}

The infection of a prosthesis hip by operative contamination remains the complication in the most formidable of this operation, the contamination surgical wounds at the end of the intervention is not exceptional, although it is of a clean surgery, with a complication rate sevenique often below 5\% [62].

The impact of the post-operative infection in surgery articular prosthetic is $3 \%$ to $5 \%$. The antibioprophylaxis allows to reduce the rate of infection to less than $0.5 \%$ [63].

In our series, the antibioprophylaxis was systematic for all patients.

\section{Tracks first and surgical technique}

The choice of a track first from the hip to the implantation of a prosthesis in total intention is the more often dictated by the habits acquired in the course of the training received by the orthopedic surgeon. The access to the hip may be earlier, anterolateral, lateral, posterolateral or posterior. The quality of a track first of the hip is often considered superior or inferior to that of another track in function of the comparisons of functional results of the Prosthetic arthroplasty performed. The objective of the surgeon who wants a total prosthesis of hip will therefore be to obtain the best compromise between the quality of operating conditions and of tissues periprothetiques [64].

\section{The PTH by navigation [64]}

The navigation by computer in the domain of the hip prosthetic surgery is the use of the computer tool in the aim of helping the orthopaedic surgeon in the planning and/or the achievement of a surgical gesture.

The installation in the supine position is classic, patient flat on the operating table under general anesthesia or rachianesthesie. The principle is to produce a digital image that will be used as a benchmark to guide the procedure by incorporating possibly by instruments.

It has been proven that the surgery of the PTH by navigation allows a better positioning of the acetabulum prosthetics.

Comparison of tracks first with the literature (Table 10)

\section{The different types of total hip prosthesis}

The PTH are distinguished primarily by their mode of fixation and according to the friction torque.

Table 10. Comparison of tracks of outskirts.

\begin{tabular}{cc}
\hline Series & Routes of Outskirts \\
\hline Archibeck et al. [26] & Track posterior external of Moore \\
Nich et al. [25] & Track posterior external of Moore: $96.4 \%$ \\
Track side with trochantérotomie & Track trans-trochantérienne \\
Courpied et al. [51] & Track posterior external of Moore \\
Series P32 [54] & Track posterior external of Moore \\
Takenaga et al. [17] & Track posterior external of Moore \\
Chana et al. [19] & Track posterior external of Moore \\
Our series &
\end{tabular}


It prefers to cement a PTH as soon as the quality of the bone is presumed or proven wrong: In patients aged among osteoporotic patients or patients with a bone pathology likely to promote the occurrence of a fracture periprothetique per or postoperative [6] [25].

\section{PTH not cemented}

The prostheses not cemented were introduced at the end of the years 70 to find out a solution to a high failure rate of cemented implants in young and active patients. In effect, the survival of the PTH is particularly important in the young subject whose life expectancy is long and the request is strong and functional [6].

The PTH not cemented are most often used in patients young and active. In effect, this mode of fixation is preferable to young adults, because it esteems the bone capital and allows a real osteo-integration, union of the living bone to the inert implant. The deference of the bone capital is also important in these subjects young people whose recovery is inevitable [6].

\section{Analysis of the means of securing in the literature}

Archibek et al., have studied the results of $100 \mathrm{PTH}$ using second generation implants not cemented in patients less than 50 years. Has 9 years of decline, they noted 13 times, 1 Sepsis on hardware, 5 prosthetic luxations, 7 case of osteolysis ( 5 cotyloidiennes Limited and 2 associated with a aseptic descellement). No cases of femoral descellement has been reported. Overall survival at 10 years was $87.5 \%$. If one takes the failure resumption of the femoral component as a criterion, the survival to 10 years was $100 \%$ and as a criterion of failure the resumption of the acetabular component, the survival was $97.1 \%$ [46].

Ryan et al., have recently reported (2014), the results of a series of 88 PTH not cemented in patients under the age of 55 years. The decline in 5 years, they noted 2 cases of recovery: 1 for prosthetic dislocation and 1 cases of sepsis on hardware. There had been no cases of descellement [22].

Kim et al., in a retrospective study, evaluated the results of 166 patients aged less than 50 years who have undergone a total hip replacement. There were 114 hybrid PTH with rods cemented and 114 PTH not cemented (all without cement) with stems not cemented. The rate of revision of the femoral components and acetabulaires were not significant between the two groups. The overall survival of the implants were similar in the 2 groups. As well, in the group "hybrid" overall survival at 10 years was $93.6 \%$ to 15 years $91.8 \%$ [33].

In the light of these results, the total prosthesis of hip implanted in patients young appears to be good, and this, whatever the mode of fixation used.

The various studies do not show the advantage of a mode of fixation by report to the other. A condition to respect the basic rules, the two modes of fixation are reliable.

In its report dating from 2007 the HAS was not able to vote for the one or the other type of fixation in young subjects [15] The analysis of the data in the literature objectively shows the satisfactory behavior of the implants not cemented in the subject less than 50 years. A condition with respect to the principles has 
been defined for the implantation of a PTH not cement. However, if the various studies carried out are state of an excellent survival for the prostheses having this mode of fixation, the problem of aseptic descellement is nevertheless not resolved. Reactions of osteolysis related to wear particles are also found, even that of migration of stemmed femoral and pain of thighs. The ablation of a PTH not cemented can be very difficult at the level of the barrel femoral and sometimes requires a component of osteotomy diaphyseal [15].

In our series the dominance of prostheses not cemented was significant. In Effect $85 \%$ of PTH were non-cemented and $15 \%$ of PTH were cemented. This choice is explained by the young age of our patients with more often a good bone quality.

\section{Friction Torque}

Within the factors likely to affect the longevity of total prosthesis of hip, and this regardless of the mode of fixation, the friction torque plays a preponderant role.

The couples of friction of arthroplasties are in constant evolution. The choice is important for young subjects in order to reduce the Chess [65].

Up until the middle of the 1990s, the majority hip prostheses included a friction torque with a metal head and a prosthesis acetabular polyethylene (metal/polyethylene). Different studies have concluded that the wear of the polyethylene was the main cause of failure. To improve the results, that is to say the duration of these arthroplasties, two major channels have been proposed: improve the couples using polyethylene or change of torque using the so-called couples hard/drive: metal/metal or ceramic/ceramic [65].

\section{Polyethylene torque-metal}

The Friction Torque conventional polyethylene-metal is the reference torque which are compared to all other couples of friction. The prostheses to conventional friction torque polyethylene-metal have the longest clinical decline. Their survival is known up to 30 years for large series of patients. The survival rates reported are $85 \%$ to 20 years, $80 \%$ to 25 years and $78 \%$ to 30 years [15].

The relationship between the wear of the polyethylene and osteolysis responsible for the aseptic descellement of the prosthesis has been shown in the literature.

The polyethylene remains the most widely used material because of its low cost and ease of manufacture [17].

\section{Conventional polyethylene}

This material of high molecular weight combines the crystals and long polymeric chains, the mechanical properties are directly related to the crystallinity and spatial cohesion of macromolecules. The disadvantage lies in the existence of free radicals, source of areas where it will happen the oxidation and therefore of wear. The wear particles cause inflammatory reactions by the intermediary of leaching of cytokine. These reactions can lead to the prosthetic explaining the descellement [66].

The retrospective series to 20 years of decline have revealed an average wear of 
$0.1 \mathrm{~mm}$ per year of the EP conventional. The survival of the implant is strongly conditioned by the presence of wear. There is a correlation between the rate of wear and tear and survival curve of the implants of PTH. Sochart et al., have demonstrated a direct relationship between the importance of the wear and the survival of the implants, if the wear is $0.1 \mathrm{~mm}$ per year, the survival to 25 years is around $70 \%$, if the wear is greater than $0.25 \mathrm{~mm}$ per year, the survival passes to less than $20 \%$ at 20 years of retreat [67].

It has been shown that the significant parameter influencing the wear of the conventional PE was the activity of the patient and the age (more than three million cycles per year among an active subject) [66].

To compensate for the failure of the conventional PE a new type of crosslinked polyethylene, source of less than wear debris and osteolysis appeared [66].

Polyethylenes highly reticulated (cross-linked polyethylene "cross-linked")

The principle is to improve the reticulation chains between the crystals by irradiation and to avoid the free radical oxidation by a thermal treatment. This change of structure must significantly improve the resistance to wear and reduce the release of particles of wear of PE. The doses of irradiation vary from 5 to $10 \mathrm{~m}$ rads and manufacturers announce a decrease of the wear between 42 and $100 \%$ compared to a conventional PE.

However, irradiation leads to alterations in the mechanical properties of polyethylene, in particular an increase in the rigidity [66].

Antonio, et al., in a retrospective and comparative study including 108 prostheses, showed a significant difference between the two types of PE. They reported a linear wear annual at 59 months of decline in average of $0.055 \mathrm{~mm} /$ year for the cotyledons uncemented polyethylene in highly reticulate, and wear annual linear to 63 months of decline on average $0.138 \mathrm{~mm} /$ year for the cotyledons not cemented in conventional polyethylene [67].

Channel Babovic et al., reports the results to medium term of PTH with PE highly reticulate in 50 patients $(54 \mathrm{PTH})$ under the age of 50 years. They reported a rate of annual wear of $0.020 \pm 0.0047 \mathrm{~mm} /$ year. Having 10 years of decline, no cases of recovery for osteolysis nor descellements of implants has been noted. Overall survival at 10 years was $100 \%$ [21].

The wear measured in the short term of cotyledons in polyethylene highly reticulate is significantly lower than that of cotyledons in conventional polyethylene. The data for long-term survival of these implants are however not yet known [15].

\section{Torque metal-metal}

The implants to a torque metal-metal, have been reintroduced at the end of the 1980s to have been widely used in the years 1950 and 1960. They are composed of an alloy of chromium and cobalt.

The prostheses using a friction torque metal-metal have an excellent resistance to wear, bringing to favor their use among the topics most actively.

It was noted in this friction torque a release of particles of chromium and cobalt in the blood, the tolerance of the body to the production of ions by the in- 
terface of friction are not yet known. The ions are eliminated by the urine, which against-indicates this torque in patients with renal impairment. A risk of carcinogenesis is mentioned, but it has never been demonstrated, reactions allergic immune against the metal ions have also described [17].

Kim, et al., in 2004 reported a series of 70 prostheses in patients less than 50 years. The average decline was 7 years, the clinical results were excellent, and no cases of descellement nor stripe have been observed after use of the torque metal-metal [68].

\section{Ceramic torque/ceramic}

The Friction Torque ceramics/ceramic has been developed and proposed as an alternative by the French Pierre Boutin since 1972. The purpose was to avoid the wear of prosthetic components and its consequences, in order to increase the longevity of implants and to enable their use in young and active patients more and more [69].

The torque ceramics/ceramic is composed of a head and an insert in ceramic massive. The insert is attached in an acetabular cup metal. Two ceramic type are used, the alumina and the zirconia.

The most used ceramic is the alumina. This torque is used since 30 years. The tolerance is excellent with a wear virtually zero: less than $0.0015 \mathrm{~mm} / \mathrm{year}$.

The behavior in friction of ceramics is very much higher than that of other couples used in arthroplasties, including the torque metal-metal. It reflects the characteristics of exceptional surface Ceramics (hardness, very low roughness, wettability, coefficient of friction very low) [69].

Chana, et al., have reported the results of 110 patients aged less than 55 years, having benefited of PTH to a torque Ceramic-ceramic. Has 10 years of decline, the wear was undetectable. The survival for the 2 components with as a criterion of failure recovery for whatever the cause was 96.5\% [29].

Baek et al., in their series, analyzed the results of $71 \mathrm{PTH}$ to a torque Ceramic-ceramic, without cement, implanted for osteonecrosis in patients less than 50 years. The average decline was 7.1 years. No cases of descellement, osteolysis or fracture of implant has been observed. In 13 patients (20\%) of the phenomena of noise have been reported [70].

In 2007 report, the HAS recommends the friction torque Ceramic-ceramic, the fact of the low production of wear debris, among patients aged less than 50 years [15].

If the torque Ceramic-ceramic proves to be competitive for young patients in terms of longevity of prosthesis, it presents however of notable drawbacks [69]:

- Risk of fracture of implants,

- Use impossible for sizes $<46 \mathrm{~mm}$, which would make the insert too fragile,

- Phenomenon of noise ("squeaking") of the torque,

- High cost.

\section{The dual mobility}

Designed by Gilles Bousquet as early as 1975, it has experienced significant growth as a result of the passage of the patent in the public domain and when 
the secondary fastening (by bone regrowth on the surface prosthetics) cupules metal-back is become reliable with the contribution of the hydroxyapatite. This type of cupule is indicated in patients with a high risk of dislocation: high age, neurological pathologies, alcoholism, low muscle trophicite, resumption of prosthesis, tumor pathology.

The problems of wear are occurring at the beginning of the experience because the surface condition and the geometry of the Prosthetic collar also intervene in the phenomena of wear, bringing in favor of smooth collar devoid of notch of extraction.

Despite a rate of wear and survival comparable to the fixed polyethylene, the risk of dislocation intraprothetique (2\%) own to this type of implant, must make their prudent indication in particular in young subjects and assets. On the other hand, it is possible to recommend their use because of their excellent stability as soon as it is a HIP to risk [17].

Phillipot et al., have reported the results of $46 \mathrm{PTH}$ to double cupule implanted mobility in subjects less than 50 years. 10 years of retreat 2 descellements acetabulaires isolated, 1 dislocated intra-prosthetics by wear of the retention and an advanced wear, have been observed. The rate of survival of overall actuarial to ten years of this cupule was $90.8 \%$. There has been no episode of prosthetic dislocation in this series [71].

In our series $15 \%$ of PTH were of type double mobility, no cases of prosthetic dislocation or intra-prosthetics was observed in these patients.

\section{Conclusions on the friction torque:}

The metal torque-polyethylene is the most used and which has the longest decline. In younger patients, the failures of this torque, are in relation with the descellement due to the wear of the polyethylene resulting in an osteolysis. The wear of the polyethylene can be decreased by the use of a head of ceramic and improving the qualities of polyethylene by reticulation (cross-linked polyethylene).

The torque metal-metal has as benefits of limited wear and the possibility of use of implants of large diameter or very large diameter. Its main drawback is the ionic leaching. The consequences of the accumulation of these ions are currently unknown.

The couple Ceramic-ceramic is the couple which has the rate of wear more low and without ionic leaching. The fracture of the ceramic, remains the main inconvenience of this couple.

In our series, the use of a torque $\mathrm{PE} /$ metal was used, because it is the least expensive, most available, and because it is accustomed to work with this material.

\section{Conclusions}

The patients, whose age are less than 50 years constitute a sub group to the characteristics and specific characteristics. In this effect, these patients usually have a physical activity still high at the time of implantation of the prosthesis, and wear of the friction surfaces is increased. In addition, their life expectancy chiefly 
makes them more likely to have undergone a resumption of their implants.

In this retrospective study of 43 patients ( 47 hips) operated before the age of 50 years between January 2008 and March 2014, we find 5 times of PTH is having a failure rate of $10.6 \%$ for a duration of mean follow-up of 42 months. But despite this failure rate, the clinical results appear more important with an average score LDCS clinic who spent 9.1 pre-operative at 16.1 in postoperative, either having average gain of 7 points.

The higher the gain has increased pain and $69.44 \%$ of hips were painless. In addition, the Final Clinical Evaluation of the patients shows an overall result judged satisfactory. These clinical results should encourage the surgeons to less restraint in the decision-making socket of the installation of a total hip among these young patients, including most of the time already multi-operated and suffering from a severe infringement of the articulation coxal-femoral. As to the choice of materials and means of mounting, the superiority (theoretical) of the friction is the torque metal-metal or ceramic.

Ceramics in terms of wear is an indisputable parameter in young subjects and assets. However, the friction torque metal-polyethylene gives good results and appears to be adapted to our context, given its availability and its cost price.

\section{References}

[1] Christofilopoulos, Lubbeke, A., Peter, R. and Hoffmeyer, P. (2010) The Point on the Total Hip. Revue Medicale Suisse, 6, 2454-2458.

[2] Delaunay, C., Aghayev, E. and Staub, L. (2009) Register of Total Prosthesis of Hip of the SOFCOT. French Society of Orthopaedic Surgery and Trauma. Report 2009.

[3] Girard, J., May, O., Krantz, N. and Migaud, H. (2011) Surgical Treatment of the Coxarthrose. EMC-Musculoskeletal Health, 2011, 1-14.

[4] Lequesne. (2009) Coxarthrose Coxopathies and of the Adult. Diagnosis and Treatment. EMC-Musculoskeletal Health, 2009, 1-21.

[5] French Society of Orthopaedic Surgery and Trauma (SOFCOT). Register of PTH of the SOFCOT, Annual Report 2013.

http://www.sofcot.fr/Pages/Registre-des-protheses-de-hanche

[6] National Agency for Accreditation and Evaluation in Health (2001) Total Prosthesis Primary Hip: Evaluation of the Choice of the Prosthesis and Operational Techniques. Paris: ANAES 2001.

[7] Pivec, R., et al. (2012) Hip Arthroplasty. Lancet, 380, 1768-1777. https://doi.org/10.1016/S0140-6736(12)60607-2

[8] Kurtz, S.M., et al. (2009) Future Young Patient Demand for Primary and Revision Joint Replacement: National projections from 2010 to 2030. Clinical Orthopaedics and Related Research, 467, 2606-2612. https://doi.org/10.1007/s11999-009-0834-6

[9] McAuley, J.P., et al. (2004) Total Hip Arthroplasty in Patients 50 Years and Younger. Clinical Orthopaedics and Related Research, 418, 119-125.

[10] Pourreyron, D., et al. (2008) Total Hip among the Young Patient. E-Memoirs of the National Academy of Surgery, 7, 42-46.

[11] Delaunay, C.P., et al. (2008) THA Using Metal-on-Metal Articulation in Active Patients Younger than 50 Years. Clinical Orthopaedics and Related Research, 466, 340-346. https://doi.org/10.1007/s11999-007-0045-y 
[12] Aldinger, P.R., et al. (2009) Uncemented Grit-Blasted Straight Tapered Titanium Stems in Patients Younger than Fifty-Five Years of Age. Fifteen to Twenty-Year Results. The Journal of Bone and Joint Surgery, 91, 1432-1439. https://doi.org/10.2106/JBJS.H.00297

[13] Migaud, H., et al. (2011) Cementless Metal-on-Metal versus Ceramic-on-Polyethylene Hip Arthroplasty in Patients Less than Fifty Years of Age: A Comparative Study with Twelve to Fourteen-Year Follow-Up. The Journal of Bone and Joint Surgery, 93, 137-142. https://doi.org/10.2106/JBJS.J.01720

[14] Hwang, K.T., et al. (2011) Cementless Total Hip Arthroplasty with a Metal-on-Metal Bearing in Patients Younger than 50 Years. Journal of Arthroplasty, 26, 1481-1487. https://doi.org/10.1016/j.arth.2011.02.020

[15] Teusink, M.J., et al. (2012) Cementless Acetabular Fixation in Patients 50 Years and Younger at 10 to 18 Years of Follow-Up. Journal of Arthroplasty, 27, 1316-1323 e2.

[16] Takenaga, R.K., et al. (2012) Cementless Total Hip Arthroplasty in Patients Fifty Years of Age or Younger: A Minimum Ten-Year Follow-Up. The Journal of Bone and Joint Surgery, 94, 2153-2159. https://doi.org/10.2106/JBJS.L.00011

[17] Innmann, M.M., et al. (2013) A Minimum Ten-Year Results of a 28-mm Metal-on-Metal Bearing in Cementless Total Hip Arthroplasty in Patients Fifty Years of Age and Younger. International Orthopaedics, 38, 929-934. https://doi.org/10.1007/s00264-013-2228-3

[18] Chana, R., et al. (2013) Ceramic-on-Ceramic Bearings in Young Patients: Outcomes and Activity Levels at Minimum Ten-Year Follow-Up. The Bone \& Joint Journal, 95-B, 1603-1609. https://doi.org/10.1302/0301-620x.95b12.30917

[19] Schmitz, M.W., et al. (2013) Clinical and Radiological Outcome of the Cemented Contemporary Acetabular Component in Patients < 50 years of Age. The Bone \& Joint Journal, 95-B, 1617-1625. https://doi.org/10.1302/0301-620x.95b12.31292

[20] Channel Babovic, N., et al. (2013) Total Hip Arthroplasty Using Highly CrossLinked Polyethylene in Patients Younger than 50 Years with Minimum 10-Year Follow-Up. The Journal of Arthroplasty, 28, 815-817. https://doi.org/10.1016/j.arth.2012.12.005

[21] Ryan, P., et al. (2014) Uncemented Primary Total Hip Arthroplasty in Patients Aged 55 Years or Younger: Results at a Minimum of 5 Years in a Consecutive Series. Orthopaedic Journal, 13, 54-60.

[22] Johnsson, R., Franzen, H. and Nilsson, L.T. (1994) Combined Survivorship and Multivariate Analyzes of Revisions in 799 Hip Prostheses. A 10-to-20-Year Review of Mechanical Loosening. Journal of Bone and Joint Surgery, 76-B, 439-443.

[23] ElKebir, L.I. (2009) The Total Hip Prostheses in the Subject of Less than Fifty Years: About 31 Cases. Department of Orthopaedics-Traumatology P32 CHU Ibn Roch. of Casablanca (CHUIR). Ph.D. Thesis, University Hassan 2 of Casablanca, Morocco.

[24] Nich, C., et al. (2006) Arthroplasty Hip to a Torque Metal-Metal on Cemented Polyethylene: Results in the Medium Term. Review of Orthopaedic Surgery and of Restorative the Device Engine, 92, 118-124.

[25] Archibeck, M.J., et al. (2006) Cementless Total Hip Arthroplasty in Patients 50 Years or Younger. Journal of Arthroplasty, 21, 476-483.

https://doi.org/10.1016/j.arth.2005.08.011

[26] Woo, R.Y. and Morrey, B.F. (1982) Dislocations after Total Hip Arthroplasty. The Journal of Bone and Joint Surgery, 64, 1295-1306.

https://doi.org/10.2106/00004623-198264090-00004

[27] Turner, R.S. (1994) Postoperative Total Hip Prosthetic Femoral Head Dislocations. 
Incidence, Etiologic Factors, and Management. Clinical Orthopaedics and Related Research, 301, 196-204.

[28] Von Knoch, M., et al. (2002) Late Dislocation after Total Hip Arthroplasty. Journal of Bone and Joint Surgery, 84-A, 1949-1953. https://doi.org/10.2106/00004623-200211000-00007

[29] Prokopetz, J.J., et al. (2012) Risk Factors for Revision of Primary Total Hip Arthroplasty: A Systematic Review. BMC Musculoskelet Disord, 13, 251. https://doi.org/10.1186/1471-2474-13-251

[30] Sedel, L. (2011) Hip Prosthesis. Medicine, 7, 393-396.

[31] Kim, Y.H., et al. (2011) Comparison of Total Hip Replacement with and without Cement in Patients Younger than 50 Years of Age: The Results at 18 Years. Journal of Bone and Joint Surgery, 93, 449-455. https://doi.org/10.1302/0301-620X.93B4.26149

[32] Guyard, Mr. and Marten, S. Total Hip for Aseptic Osteonecrosis of the Femoral Head: Analysis of a Series of 128 Arthroplasties at Minimum Setback of 24 Months. Lyons Days of Surgery of the Hip 2008.

[33] Parratte, S., Flecher, X., Aubaniac, J.-M. and Argenson, J.N. Total Hip Not Cemented onto Measure for Aseptic Osteonecrosis of the Femoral Head in Young Subjects. Lyons Days of Surgery of the Hip 2008.

[34] Radl, R., et al. (2005) Higher Failure Rate and Stem Migration of Year Uncemented Femoral Component in Patients with Femoral Head Osteonecrosis than in Patients with Osteoarthrosis. Acta Orthopaedica, 76, 49-55.

https://doi.org/10.1080/00016470510030319

[35] Ince, A., et al. (2006) No Increased Stem Subsidence after Arthroplasty in Young Patients with Femoral Head Osteonecrosis: 41 Patients Followed for 1-9 Years. Acta Orthopaedica, 77, 866-870. https://doi.org/10.1080/17453670610013141

[36] Min, B., et al. (2008) Second-Generation Cementless Total Hip Arthroplasty in Patients with Osteonecrosis of the Femoral Head. The Journal of Arthroplasty, 23, 902-910. https://doi.org/10.1016/j.arth.2007.07.021

[37] Wegrzyn, J., Durand, J.M. and Bejui-Hugues, J. (2015) Total Hip without Cement in the Inflammatory Arthritis (in the Case of Rheumatoid Arthritis). Lyons Days of Surgery of the Hip 2008.

[38] Eskelinen, A., et al. (2006) Total Hip Arthroplasty for Rheumatoid Arthritis in Younger Patients: 2,557 Replacements in the Finnish Arthroplasty Register Suivie for 0-24 Years. Acta Orthopaedica, 77, 853-865. https://doi.org/10.1080/17453670610013132

[39] Fontaine, V. (2014) Surgery of the Rheumatoid Arthritis. EMC-Musculoskeletal Health, 9, 1-22.

[40] Hartofilakidis, G. and Karachalios, T. (2004) Total Hip Arthroplasty for Congenital Hip Disease. The Journal of Bone and Joint Surgery, 86-A, 242-250. https://doi.org/10.2106/00004623-200402000-00005

[41] Faldini, C., et al. (2011) Congenital Hip Dysplasia Treated by Total Hip Arthroplasty Using Cementless Tapered Stem in Patients Younger than 50 Years old: Results after 12-Years Follow-Up. The journal of Orthopaedics and Traumatology, 12, 213-218. https://doi.org/10.1007/s10195-011-0170-y

[42] Pidhorz, L. and Sedel, L. (1998) The Total Prosthesis of Hip before 50 Years. Revue De Chirurgie Orthopedique Et Reparatrice De L'Appareil Moteur, 84, 75-120.

[43] Flecher, X., Aubaniac, J.M. and Argenson, J.N. (2013) Total Hip Replacement for Congenital Dislocation. EMC-Surgical Techniques-Orthopedie-Traumatologie, 8, 
$1-9$.

[44] Thillemann, T.M., et al. (2008) Implant Survival after Primary Total Hip Arthroplasty Due to Childhood Hip Disorders: Results from the Danish Hip Arthroplasty Registry. Acta Orthopaedica, 79, 769-776. https://doi.org/10.1080/17453670810016830

[45] Furnes, O., et al. (2001) Hip Disease and the Prognosis of Total Hip Replacements-A Review of 53698 Primary Total Hip Replacements Reported to the Norwegian Arthroplasty Register 1987-99. Journal of Bone and Joint Surgery, 83-B, 579-586. https://doi.org/10.1302/0301-620X.83B4.11223

[46] Abdelfettah, Y., et al. (2013) Functional Outcomes after Surgery of Para-OsteoArthropathies Neurogenic at the CHU in Casablanca, Morocco. Journal of Medical Rehabilitation: Practice and Training in Physical Medicine and Rehabilitation, 33, 20-25.

[47] Bouattour, K., et al. (2008) Results of the Surgical Treatment of Neurogenic Osteomas of the Hip: About 30 Cases. Tunisian Society of Orthopaedics and Traumatology, 1, 171-177.

[48] Sorriaux, G., et al. (2004) Articular Impact of Para-Osteo-Neurogenic Arthropathies Ankylosant the Hip: Therapeutic Consequences. Review of Orthopaedic Surgery and of Restorative the Device Engine, 90, 216.

[49] Witvoet. (1995) Criticism of Methods for the Assessment of the Surgery-Prosthetics of the Hip Paris: Expansion French Scientific, Cahiers d'enseignement de la SOFCOT $n^{\circ} 52,11-22$.

[50] Aubigne, R.M. and Postel, M. (1954) Functional Results of Hip Arthroplasty with Acrylic Prosthesis. The Journal of Bone and Joint Surgery, 36, 451-475. https://doi.org/10.2106/00004623-195436030-00001

[51] Blanchard-Dauphin. (2005) Assessment of the Functional Disability and Quality of Life in Orthopaedics. EMC-Musculoskeletal Health, 2005, 1-24.

[52] Courpied, et al. (2005) Long-Term Results of the Total Hip Replacement by Prosthesis Kerboull Charnley in the Subject of Less than 50 Years. Review of Orthopaedic Surgery and of Restorative the Device Engine, 91, 355-357.

[53] Vidalain, J.P. and Cartillier, J.C. (2005) Prospective Analysis of a Continuous Series of 120 Coral Prostheses. Review of Orthopaedic Surgery and of Restorative the Device Engine, 91, 364-365.

[54] Nourissat, C. and Cartillier, J.C. (2007) Technique of Setting in Place the Total Prosthesis of Hip without Cement. EMC-Surgical Techniques-Orthopedie-Traumatologie, 2007, 44-667.

[55] Chassery, C., et al. (2010) Anesthesia and Taken in Charge of the Pain in the Occasions of Total Hip: Anesthesia in Hip Arthroplasty Revision, in Resumption of Prostheses of Hips. Elsevier Masson, Paris, 74-84.

[56] Carles, M., Blay, M. and Gaertner, E. (2011) Anesthésie en chirurgie orthopédique. EMC-Anesthésie-Réanimation, 2011, 1-13, Article 36-605-A-10.

[57] Rodgers, A., et al. (2000) Reduction of Postoperative Mortality and Morbidity with Epidural or Spinal Anesthesia: Results from Overview of Randomized Trials. British Medical Journal, 321, 1493. https://doi.org/10.1136/bmj.321.7275.1493

[58] Mauermann, W.J., Shilling, A.M. and Zuo, Z.A. (2006) Comparison of Neuraxial Block versus General Anesthesia for Elective Total Hip Replacement: A Meta-Analysis. Anesthesia \& Analgesia, 103, 1018-1025. https://doi.org/10.1213/01.ane.0000237267.75543.59

[59] Macfarlane, A.J., et al. (2009) Does Regional Anesthesia Improve Outcome after 
Total Hip Arthroplasty? A Systematic Review. British Journal of Anaesthesia, 103, 335-345. https://doi.org/10.1093/bja/aep208

[60] Choi, P.T., et al. (2009) Epidural Analgesia for Pain Relief Following Hip or Knee Replacement. The Cochrane Database of Systematic Reviews, 3, CD003071.

[61] Opperer, M.R., et al. (2014) Perioperative Outcomes and Type of Anesthesia in Hip Surgical Patients: Year Evidence-Based Review. World Journal of Orthopaedics, 5, 336-343. https://doi.org/10.5312/wjo.v5.i3.336

[62] Swierstra, B.A., et al. (2011) Dutch Guideline on Total Hip Prosthesis. Acta Orthopaedica, 82, 567-576. https://doi.org/10.3109/17453674.2011.623575

[63] Dudkiewicz, I., et al. (2000) Total Hip Arthroplasty after Childhood Septic Hip in Patients Younger than 25 Years of Age. The Journal of Pediatric Orthopaedics, 20 585-587. https://doi.org/10.1097/01241398-200009000-00008

[64] Lahyat, B., et al. (2005) Antibiotic Prophylaxis in Surgery Traumato-Orthopedic. Revue Chirurgie Orthopédique et Traumatologique Maroc, 23, 42-45.

[65] Eskelinen, A., et al. (2006) Uncemented Total Hip Arthroplasty for Primary Osteoarthritis in Young Patients: A Mid-to Long-Term Follow-Up Study from the Finnish Arthroplasty Register. Acta Orthopaedica, 77, 57-70.

https://doi.org/10.1080/17453670610045704

[66] Lifted Up, J., Descamps, S. and Boisgard, S. (2011) The Friction Torque in the Total Arthroplasties of Hip. E-Submissions of the National Academy of Surgery, 10, 19-22.

[67] Sochart, D.H. and Wear, M.L. (1997) The Long-Term Results of Charnley Low Friction-Arthroplasty in Young Patients Who Have Congenital Dislocation, Degenerative Osteoarthrosis, Gold Rheumatoid Arthritis. The Journal of Bone and Joint Surgery, 79, 1599-1617. https://doi.org/10.2106/00004623-199711000-00001

[68] Antonio, J.A., et al. (2005) Five-Year Experience with Crossfire (R) Highly Cross-Linked Polyethylene. Clinical Orthopaedics and Related Research, 441, 143150. https://doi.org/10.1097/00003086-200512000-00024

[69] Kim, S.Y., et al. (2004) Cementless Metasul Metal-on-Metal Total Hip Arthroplasty in Patients Less than Fifty Years Old. The Journal of Bone and Joint Surgery, 86 2475-2481. https://doi.org/10.2106/00004623-200411000-00018

[70] Bizot, P. (2010) The Torque Ceramic-Ceramic in the Total Arthroplasties of Hip. Teaching of the SOFCOT, 99, 279-303.

[71] Baek, S.H. and Kim, S.Y. (2008) Cementless Total Hip Arthroplasty with Alumina Bearings in Patients Younger than Fifty with Femoral Head Osteonecrosis. The Journal of Bone and Joint Surgery, 90, 1314-1320. https://doi.org/10.2106/JBJS.G.00755 
Submit or recommend next manuscript to SCIRP and we will provide best service for you:

Accepting pre-submission inquiries through Email, Facebook, LinkedIn, Twitter, etc. A wide selection of journals (inclusive of 9 subjects, more than 200 journals)

Providing 24-hour high-quality service

User-friendly online submission system

Fair and swift peer-review system

Efficient typesetting and proofreading procedure

Display of the result of downloads and visits, as well as the number of cited articles Maximum dissemination of your research work

Submit your manuscript at: http://papersubmission.scirp.org/

Or contact ojem@scirp.org 